\title{
Safe-economical route model of a ship to avoid tropical cyclones using dynamic forecast environment
}

\author{
L. $\mathbf{W u}^{1,2,3}$, Y. Wen ${ }^{1,3}$, D. Wu ${ }^{1,3}$, J. Zhang ${ }^{1,3}$, and C. Xiao ${ }^{1,3}$ \\ ${ }^{1}$ Hubei Inland Shipping Technology Key Laboratory, Wuhan, China \\ ${ }^{2}$ Department of Earth Science, Uppsala University, Uppsala, Sweden \\ ${ }^{3}$ School of Navigation, Wuhan University of Technology, Wuhan, China
}

Received: 23 July 2014 - Accepted: 23 July 2014 - Published: 4 August 2014

Correspondence to: L. Wu (wulichuan0704@gmail.com)

Published by Copernicus Publications on behalf of the European Geosciences Union.

\begin{abstract}
In heavy sea conditions related to tropical cyclones (TCs), losses to shipping caused by capsizing are greater than other kinds of accidents. Therefore, it is important to consider capsizing risk in the algorithms used to generate safe-economic routes that 5 avoid tropical cyclones (RATC). A safe-economic routing and assessment model for RATC, based on a dynamic forecasting environment, is presented in this paper. In the proposed model, a ship's risk is quantified using its capsizing probability caused by heavy wave conditions. Forecasting errors in the numerical models are considered in the ship risk assessment according to their distribution characteristics. A case study

10 shows that: the economic cost of RATCs is associated not only to the ship's speed, but also to the acceptable capsizing probability which is related with the ship's characteristic and the cargo loading condition. Case study results demonstrate that the optimal routes obtained from the model proposed in this paper are superior to those produced by traditional methods.
\end{abstract}

\section{Introduction}

As a major transportation mode, maritime transportation plays an important role in the international trade. The daily operating costs of a ship can be tens of thousands of dollars. The problems of ship routing and scheduling have been often addressed by scientists and engineers during the last decades (Christiansen et al., 2004). Linear

20 programming model (LP), mixed integer programming (MIP) model and set partitioning (SP) formulation are used to solve the routing problem. Various methods such as Dijkstra's algorithm, semi-Markov decision process etc. (Azaron and Kianfar, 2003) have been used to address the optimization problem of ship routing.

In the ship routing, weather hazards are the main factor needed to be considered.

25 The goal of weather routing is to plan routes that avoid weather hazards safely and economically. Tropical Cyclones (TCs), as a kind of hazardous weather, often cause 
extensive damage to the ship and crew. Ships can avoid TCs safely with routes based on the methods applied in navigation practice - sector diagram typhoon avoidance method (Chen and Zhang, 2004); 34KT rule (Holweg, 2000); and the Diagram of the 1-2-3 rule (Wisniewski et al., 2009) - but these methods are limited. For example, 5 the crew's experience is used in these methods to estimate the ship's risk, instead of quantifying the risk according to the ship's performance. Lots of scholars have tried kinds of approaches to quantify the ship risk in recent years (i.e. Shi et al., 2011). But few of these methods have been used to design the ship routes that avoid tropical cyclones (RATC).

10 Weather routing is a ship routing problem with multiple restrictions and changing environment conditions. Before elaborating the model of RATC, the relevant research progresses related with this topic are simply summarized, which includes numerical forecast errors, ship routes that avoid tropical cyclones (RATC), and vessel risk analysis.

15 There are several widely used methods for weather routing. These methods are based on the isochrone method and have been refined and widely used for decades since its introduction by James (1957) and its improvement by Hagiwara (1989). Chen (1978) developed a dynamic programming algorithm to solve the minimum voyage cost problem under uncertainty constraints. In the algorithm, the sea-keeping features of 20 the ship are a function of weather. McCord et al. (1999) investigated the potential for strategic ship routing through dynamic currents to determine 3 day routes. The results showed that this kind of strategic ship routing can reduce fuel consumption by $25 \%$ on average. Delitala et al. (2010) showed that weather routing improves ship performance by $37 \%$ thus supporting ship captains throughout an entire voyage. Panigrahi

25 et al. (2008) and Padhy et al. (2008) optimized the ship's route based on the output of the WAM (WAve Model). Maki et al. (2011) designed a real-coded genetic algorithm for weather routing to calculate the safety ratio and fuel efficiency based on the probability of accidents caused by parametric rolling. Soda et al. (2011) gathered and used high-resolution wind and wave data forecasted by SWAN (Simulating Waves Nearshore

4909

model) and WRF (Weather Research and Forecasting Model) to study wave and wind effects on ship's manoeuvring. From the aspect of minimum probability of coastal pollution, fairways in the Gulf of Finland are designed based on high-resolution modelled ocean currents (Andrejev et al., 2011).

The weather routing problem is complicated since weather conditions are uncertain. The forecast error in numerical models must be considered when designing weather routing (Magirou and Psaraftis, 1992). Hopkins (1997) examined the statistical errors of the offshore forecast derived from the numerical forecasting models. RMS (root mean square) deviation in wind speed and wave height forecasts has a seasonal variation.

10 The RMS deviation of the WaveWatchlll model against altimeter and buoy data are $15 \%$ of the mean observed wave height for most of the global domain (Tolman, 2002). Bedard (2008) evaluated the forecast performance of WaveWatchlll based on the comparison of its output with buoy-measured wave data in deep water of Washington and Oregon, USA Compared with the T/P (Topex/Poseidon) significant wave height (SWH)

15 data, Chu et al. (2004) found that the forecast errors of SWH in WaveWatchlll has a Gaussian-type distribution in South China Sea (SCS), similarly to the conclusion of Guo and Hou (2010).

Although the literature on weather routing is rich, little work focuses on RATC. The sector diagram typhoon avoidance method (Chen, 2004), and the 34KT rule (Holweg,

20 2000) are widely used in navigation. Wisniewski (2009) discussed the application of the 1-2-3 rule for calculations for routing vessels using evolutionary algorithms. Liu et al. (2006) built a safety-economic decision-making model of RATC using risk theory and fuzzy information optimization. Zhang et al. (2010) proposed a multilevel decision method for RATC using multi-source track forecasting. Wu et al. (2010) built a model to

25 evaluate the benefit of RATC. Wisniewski and Kaczmarek (2012) analysed ship reactions, such as reducing speed and changing course, when a ship is avoiding a TC. At present, these RATC methods are mainly based on TC forecast tracking, experience, and fuzzy analysis. All these methods, in the final instance rely on qualitative judgements. These methods also do not consider the performance or reactions of different 
vessels under the same wave or wind conditions. Therefore, different vessels might require different routing strategies to safely and economically avoid tropical cyclones (TCs).

The quantification of risk to ships under heavy weather conditions is an important 5 problem for weather routing. However, most researchers assess a ship's risk qualitatively using fuzzy analysis (Zhang et al., 2010; Liu et al., 2006). In heavy sea conditions related to TCs, capsizing leads to the total loss of ship and cargo, that is, to much greater losses than other kinds of accidents. So, it is reasonable to consider the capsizing probability as the major contribution to the risk in RATC. In recent years, cap-

10 sizing probability has received attention as an empirical measure to quantify the ship's risk. Shen and Huang (2000) studied the time until the ship capsizes and the capsizing probability of ship based on Markov chain theory. Huang et al. (2001) studied the capsizing probability of a ship under the combined action of beam wind and beam sea. In this method, the capsizing probability of every random heeling in an unstable domain is

15 calculated according to the probability density of the extreme values of heeling. Thompson (Thompson, 1990; Thompson et al., 1992) used the theory of safe basis erosion to study the ship capsizing probability. Shi et al. (2011) studied the calculation method of ship's movement and capsizing probability in random waves and winds using the formula of Gauss-Legendre based on the path integration techniques. Gu (2006a) cal-

20 culated the ship's rolling probability using a new path integration method, which avoided the problem of solving the equations of Fokker-Planck-Kolmogorov (FPK). The method of Melnikov is also used to calculate the ship's capsizing probability (Falzarano et al., 1992; Bikdashi et al., 1994; Tang et al., 2004).

Based on work related to weather routing summarized above, we can conclude that 25 the resolution and precision of ocean and atmospheric models are increasing in tandem with the rapid development of computational power, thus allowing more possibilities for ship routing with more precise and less uncertain forecast results (Delitala et al., 2010). Many researchers addressed various aspects of weather routing using ocean and weather numerical models, but the forecast errors of models are usually

4911

not considered in their works (Padhy et al., 2008; Maki et al., 2011). The quantitative assessment of the ship risk in the RATC is rarely seem in literature. There are little research about the evaluation the economic benefit of a RATC. Wu et al. (2013) constructed a model to optimize the route to avoid a TC using numerical model results.

5 But, in their model, the risk areas, which the ship cannot navigate, are simply treated as where the wind speed is higher than a certain value. The forecast errors were not considered in their model, either. As a continues study, in this paper, a minimum economic cost route was designed to avoid TCs from the following aspects: (1) the forecast errors of models are dealt with in the route design, (2) the ship's characteristics 0 are considered in assessing the risk in the heavy weather conditions, (3) the ship's risk is quantified, (4) the ship's speed loss is accounted for. The cost-benefit ratio of RATC was proposed to assess the performance of a route.

In the following, Sect. 2 describes the mathematical model of RATC. Section 3 introduces how we assessed the ship risk using the capsizing probability and which method 15 we used to calculate the ship speed loss and deal with the forecast errors. The algorithm of RATC was proposed in Sect. 3.2. In Sect. 4, a case was choose to test the superiority of the proposed model, and Sect. 5 gives the conclusions.

\section{Mathematical model}

The movement of a ship sailing on the ocean can be described as the change of ship's position over time. The ship's position ( $x$ (lon, lat)) and time $(t)$ form the ship's track. The ship's dynamic response to varying environmental conditions (including the ship's heading direction and speed) can be described by a function with a control vector $U$ and restraint vector $\boldsymbol{M}$. Then, the dynamic process of advancement of a ship can be expressed as:

$25(x, t)=f\left(x^{\prime}, t^{\prime}, E, \boldsymbol{U}, \boldsymbol{M}\right)$ 
in which, $t^{\prime}=t-\Delta t, E$ is the external environment at location $x^{\prime}$ at time $t^{\prime}$. The ship is controlled by $U$ during time $\Delta t$. The ship will arrive at location $x$ at time $t$. The economic $\operatorname{cost} C_{\text {cost }}$ of the whole voyage can be expressed as:

$C_{\text {cost }}=\int_{T_{0}}^{T}\left\{C_{\text {oil }}\left(\Delta, V, Q_{\mathrm{a}}\right)+C_{\mathrm{t}}\right\}$

in which, $C_{\text {oil }}$ is the fuel consumption per unit time, $C_{\text {oil }} \propto \Delta^{2 / 3} \cdot V \cdot Q_{\mathrm{a}}, Q_{\mathrm{a}}$ is the oil price, $\Delta$ is the ship displacement, $C_{\mathrm{t}}$ is the ship's profitability per unit time, and related to the type of the ship and its production plan, $V$ is the ship speed.

How to improve the economic benefit of a ship based on safety criteria is the con-

10 cept behind of RATC. An economical and safe RATC based on a dynamic forecasting environment can increases ship safety and reduces costs. Costs may be very different given the same risk because of the difference of the ships' type and their cargo's value. To assess the economic benefit of RATC, a cost-benefit ratio for a route is built. A ship's safety can be evaluated as the probability of safety multiplied by the ship's fixed assets 15 including the value of both ship and cargo. Then, the cost-benefit ratio (Ra) of RATC can be expressed as:

$\mathrm{Ra}=\frac{C_{\text {cost }}}{M_{\text {all }} \cdot P_{\text {safe }}}$

where, $C_{\text {cost }}$ is the economic cost of the whole voyage, including the time cost and

20 fuel consumption, $P_{\text {safe }}$ is the safety probability of ship, considered as the probability that ship will not capsize, $M_{\mathrm{all}}$ is the value of the ship and the cargo, $\mathrm{Ra}$ is the total cost of ensuring the ship's economic safety in economic cost units when avoiding TCs. Therefore, the smaller the $\mathrm{Ra}$ is, the less it takes to ensure a ship's safety when avoiding TCs.

The mathematical model for RATC can be considered as a ship's avoidance of an obstruction that changes shape and position over time. The probability of ship accident 4913

must not exceed an acceptable risk level for the operator. Let us assume that a ship begins to take an action to avoid TC at time $t_{0}$, and will pass through the TC after time $T$. Then, during time $T$, the ship's speed and course will change predetermined route. The points at which the ship's speed or course is changed are considered to be 5 waypoints. The avoidance process is regarded as complete when the ship arrives at the next waypoint of the original predetermined route. The whole process of avoiding the TC therefore, can be regarded as an optimal path problem.

Let us choose $x_{0}$ as the starting point for a ship to avoid a TC, $x_{n}(n=1,2, \ldots \ldots)$ are the alternative waypoints of the route, $l_{i, i+1}$ is a segment of the route between

10 two adjacent alternative waypoints, $d_{i, i+1}$ is the distance between any two adjacent alternative waypoints, $p_{i, i+1}$ is the probability of a ship accident in a unit of time between any two adjacent alternative waypoints, and $v_{i, i+1}$ is the average speed-to-ground when ship is sailing on segment $I_{i, i+1}$. Then, the ship's safety probability $P_{\text {safe }}$ in the whole process is:

$15 \quad P_{\text {safe }}=\prod_{i=1}^{n}\left(1-p_{i-1, i}\right)$.

The economic cost in the whole process is:

$C_{\mathrm{cost}}=\sum_{i=1}^{n} \frac{d_{i-1, i}}{v_{i-1, i}} \cdot\left(C_{\mathrm{t}}+C_{\mathrm{oil}}\right)$.

20 The cost-benefit ratio $(\mathrm{Ra})$ of the route is:

$\mathrm{Ra}=\frac{\sum_{i=1}^{k} \frac{d_{i-1, i}}{v_{i-1, i}}\left(C_{\mathrm{t}}+C_{\mathrm{oil}}\right)}{M_{\mathrm{all}} \cdot \prod_{i=1}^{k}\left[\left(1-p_{i-1, i}\right)\right]}$

The acceptable risk level restriction is, $p_{i-1, i}<p_{\mathrm{a}}$. In which, $p_{\mathrm{a}}$ is the acceptable accident probability of ship capsizing, $i$ is an alternative waypoint of the route, $k$ is the 25 amount of the alternative waypoints. 
The most economical route (the minimum economical cost route) based on the safety is $\min \left\{C_{\text {cost }}\right\}$.

\section{The RATC algorithm}

\subsection{Relevant parameters}

\section{3.1.1 Ship capsizing probability}

Waves may be excited by wind during TCs. Wind and waves are strongly correlated. In this paper, the ship risk is simplified using the probability of capsizing in random waves. Several methods are used to calculate the probability of ship capsizing in waves, i.e. Safe basis erosion method (Thompson, 1990; Thompson et al., 1992), GaussLegendre (Shi et al., 2011), Melnikov (Bikdashi et al., 1994; Tang et al., 2004).

The differential equation of ship's nonlinear rolling motion in random wave conditions is $(\mathrm{Gu}, 2006 \mathrm{~b})$ :

$$
\left(I+I_{1}(\omega)\right) \ddot{\phi}+B_{1}(\omega) \dot{\phi}+B_{2}(\omega) \dot{\phi}^{3}+\Delta G Z=F_{\text {sea }}(t)
$$

15 where, $I$ is the rotational moment of inertia around an assumed rolling centre, $I_{1}(\omega)$ is the added moment of inertia due to the ambient fluid, $B_{1}$ and $B_{2}$ are linear and cubic damping coefficients respectively, $\Delta$ is the ship displacement, $G Z$ is the righting arm of a rolling ship, $F_{\text {sea }}(t)$ is the external excitation resulting from random beam seas, the over-dots denote differentiation with respect to time $t, \omega$ is the wave angular frequency 20 in radians, $\phi$ stands for ship's roll angle.

The righting arm is approximated by the following odd cubic polynomial of $\phi$,

$\mathrm{GZ}(\phi)=C_{1} \phi-C_{3} \phi^{3}$.

4915

The excitation moment resulting from the random seas is expressed as:

$F_{\text {sea }}(t)=I_{0} \alpha_{0} \omega_{0}^{2} \frac{\sqrt{2 \varpi}}{g} \sum_{n=1}^{N}(n \varpi)^{2} \sqrt{S} \cos \left(\omega_{\text {en }} t+\xi_{n}\right)$,

in which, $I_{0}=I+I_{1}(\omega), \alpha_{0}$ is the effective wave slope, $\omega_{0}$ is the natural frequency of 5 ship's roll, $\varpi$ is the interval of wave frequency, $S$ is the excitation intensity of white noise, $\xi_{n}$ is the random phase angle in $(0,2 \pi), g$ is gravitational acceleration.

When a ship is at sea, $\chi$ is the angle of wave encounter between the heading direction and wave direction as illustrated in Fig. 1. Also shown in Fig. 1 are the ship's breadth, $B$, the ship's speed, $\mu$, the wavelength, $\lambda$. The encounter frequency between wave and ship $\omega_{\mathrm{e}}$ is (Tang et al., 2006):

$\omega_{\mathrm{e}}=\omega-\frac{\omega^{2}}{g} \mu \cos \chi$.

The encounter spectrum's relationship with the wave spectrum:

$$
S_{\mathrm{e}}(\omega)=\frac{S(\omega)}{1-(2 \omega / g) \mu \cos \chi} \text {. }
$$

The wave spectrum, with single parameter, as specified by the ITTC (International Towing Tank Conference) (Kaplan, 1966) was used:

$S(\omega)=\frac{A}{\omega^{5}} \exp \left\{-\frac{B}{\omega^{4}}\right\}$

20 where, $A=8.10 \times 10^{-3} g^{2}, B=3.11 / H_{1 / 3}^{2}, H_{1 / 3}$ is the SWH.

Therefore, the wave excitation torque for random waves is calculated using the following formula:

$$
F_{\text {sea }}(t)=I_{0} \alpha_{0} \omega_{0}^{2} \frac{\sqrt{2 \varpi}}{g} \sum_{n=1}^{N}(n \varpi)^{2} \sqrt{S} \cos \left(\left(\omega_{\mathrm{e}}\right)_{n} t+\xi_{n}\right),
$$


in which, wave height $h_{n}=2 \sqrt{2 \varpi S(n \varpi)}$ and wave length $\lambda_{n}=\frac{2 \pi g}{(n \varpi)^{2}}$.

The non-dimensional form of Eq. (7), the differential equation for a ship's rolling motion in random seas, in which the white noise is considered, is as following (Gu, 2006b, 2004),

${ }_{5} \quad \ddot{x}(\tau)+\varepsilon \delta_{1} \dot{x}(\tau)+\varepsilon \delta_{2} \dot{x}^{3}(\tau)+x(\tau)-\alpha x^{3}(\tau)=\varepsilon f(\tau)$,

in which, $x=\phi, \tau=\omega_{0} t, \varepsilon \delta_{1}=\frac{B_{1}(\omega)}{\Delta C_{1}} \omega_{0}, \varepsilon \delta_{2}=\frac{B_{2}(\omega)}{I+l_{1}(\omega)} \omega_{0}, \alpha=\frac{C_{3}}{C_{1}}, \Omega=\frac{\omega}{\omega_{0}}, \omega_{0}=\sqrt{\frac{\Delta C_{1}}{l+l_{1}(\omega)}}$, $\varepsilon f(\tau)=\frac{F_{\text {sea }}(t)}{\Delta C_{1}}, \varepsilon$ is a parameter of small values, $f(\tau)$ is the excitation and differentiation with respect to non-dimensional time $\tau, \varepsilon \delta_{1}$ and $\varepsilon \delta_{2}$ are the dimensionless linear and 10 quadratic viscous damping coefficient respectively, $\alpha$ is the strength of the non-linearity.

The joint probability density of $\phi$ and $\dot{\phi}$ can be found by solving the corresponding Fokker-Planck-Kolmogorov (FPK) equation for Eq. (14). In this paper the method proposed by Gu (2006b) was used to solve the FPK equation. The joint probability is:

$P_{\mathrm{F}}\left(x_{1}, x_{2} \mid \phi\right)=\operatorname{aexp}\left\{-\frac{\phi}{D}\left(\frac{x_{1}^{2}}{2}-\alpha \frac{x_{1}^{4}}{4}\right)\right\} \exp \left\{-\frac{1}{D}\left(\delta_{1} \frac{x_{2}^{2}}{2}+\delta_{2} \frac{x_{2}^{4}}{4}\right)\right\}$

in which,

$\phi=\frac{\int_{0}^{\infty} x_{2}\left(\delta_{1} x_{2}+\delta_{2} x_{2}^{3}\right) \exp \left\{-\frac{1}{D}\left(\delta_{1} \frac{x_{2}^{2}}{2}+\delta_{2} \frac{x_{2}^{4}}{4}\right)\right\} d x_{2}}{\int_{0}^{\infty} x_{2}^{2} \exp \left\{-\frac{1}{D}\left(\delta_{1} \frac{x_{2}^{2}}{2}+\delta_{2} \frac{x_{2}^{4}}{4}\right)\right\} \mathrm{d} x_{2}}$,

$a$ is a normalizing parameter which can be calculated using the following formula:

$20 \int_{-\infty}^{+\infty} \int_{-\infty}^{+\infty} P_{\mathrm{F}}\left(x_{1}, x_{2} \mid \phi\right) \mathrm{d} x_{1} \mathrm{~d} x_{2}=1$

4917

$D$ is the amplitude of excitation.

Then, the marginal probability density of $\varphi$ can be calculated based on the joint probability density. Thus, the ship capsizing probability $P$ can be calculated using the following formula:

$5=\max \left\{\int_{\phi_{v 1}}^{+\infty} P\left(x_{1}, t\right) \mathrm{d} x_{1}, \int_{-\infty}^{\phi_{v 2}} P\left(x_{1}, t\right) \mathrm{d} x_{1}\right\}$,

in which, $\phi_{v 1}$ and $\phi_{v 2}$ are the angle at which positive and negative stability disappears respectively, $P\left(x_{1}, t\right)$ is the marginal probability density.

\subsubsection{Ship speed loss in waves}

10 Ship speed loss in waves has an important effect on the estimate of the ship's location in the design of RATC. If the ship's speed loss is not considered, it will cause error when calculating the ship's position over time. At present, there are many empirical formulas to estimate the ship speed loss due to waves (Aertssen, 1969; James, 1957; Li et al., 2011). In this paper, however, the formula proposed by He and Dong (2009) is used to 15 estimate the ship speed loss in the heavy conditions. The formulas can be expressed as follow:

$\frac{\Delta V}{V}=\frac{12 \cdot \frac{B}{T} \cdot C_{\mathrm{w}}}{\left[0.45 \cdot\left(\frac{L}{100}\right)^{2}+0.35 \cdot \frac{L}{100}\right] \cdot L}$

in which, $\Delta V$ is the ship's speed loss in waves, unit: [knots], $V$ is the ship's design 20 speed, unit: [knots], $L$ is the length of two makefasts, unit: [m], $B$ is the ship's breadth, unit: [m], $T$ is the ship's draft, unit: [m], $C_{\mathrm{w}}$ is the index of wave grade, which can be calculated using $C_{\mathrm{w}}=K \cdot T_{1} \cdot H_{1 / 3}^{2}, K$ is the correction factor, which can be calculated 
using the following formula:

$K= \begin{cases}-0.05 H_{1 / 3}+0.9 & L \leq 150 \\ 1.3 & 150<L<200 \\ 0.0125 \cdot H_{1 / 3}^{2}+0.05 H_{1 / 3}+0.7375 & L \geq 200\end{cases}$

in which, $H_{1 / 3}$ is the SWH, unit: [m], $T_{1}$ is the wave period, unit: [s].

\section{3.1.3 Forecast error of numerical model}

The forecast errors from numerical models are mainly caused by inaccurate initial and boundary conditions. If forecasting errors are not considered in designing RATC, the calculation of ship's risk will have significant errors. The SWH and wave frequency (wave period) errors are important when calculating a ship capsizing probability.

Using measurements from satellite, the errors of the SWH from the wave model were assessed by many researchers (i.e. Chu et al., 2004; Guo and Hou, 2010). In our case, it is not straightforward to evaluate the distribution of the forecast errors of wave period because most of the available measurements have been performed near the shore. Zhou et al. (2012) found that WaveWatchlll underestimated the wave period in

15 the SCS (see their Fig. 5). According to Gu and Miao (2005), under the same SWH, the smaller the wave period, the higher the ship capsizing probability. Thus, using the wave period from WaveWatchlll will overestimate the ship capsizing probability. Such an overestimation is acceptable in navigation practice, because the ship can avoid the high risk area far away based on the model results. Thus, the forecast errors of wave period

20 in the model are not considered in the model. They can be taken into consideration using the same method as SWH errors (below) when the data are enough to conclude the forecast errors distribution.

Chu et al. (2004) found that the SWH errors from WaveWatchlll have a Gaussiantype distribution with a small mean $(\mu)$ value of $0.02 \mathrm{~m}$, as compared with the T/P 25 altimeter data in the SCS. The RMS deviation $(\sigma)$ and correlation coefficient between 4919

the modelled $\left(H_{\mathrm{m}}\right)$ and observed $\left(H_{\mathrm{o}}\right) \mathrm{SWH}$ are $0.48 \mathrm{~m}$ and 0.90 respectively. In their research, 1330 samples were used for statistical analysis.

Taking the error range into consideration, a ship capsizing probability was calculated based on the distribution of the wave model forecast errors of SWH. In this paper, the 5 error range was processed using the truncation method. Because the probability of errors bigger than $2 m$ or less than $-2 m$ is only 0.019 , this paper only considers the error range $[-2,2]$. The division of the error range $\Delta E_{i}$ is shown in Table 1 , and the probability for each error subdivision is $\Delta r_{i}$. According to the forecasted value of the wave height and the error subdivision, the probability of ship capsizing $\Delta p_{i}$ in each error 10 subdivision can be calculated. Because the SWH is positive, we treat the probability of capsizing in the negative SWH (forecast SWH adding the forecast error) as 0 . Then, the capsizing probability $p$ of a ship in the forecast condition can be calculated using the following formula:

$p=\sum_{i=1}^{8} \frac{\Delta r_{i} \cdot \Delta p_{i}}{\sum_{i=1}^{8} \Delta r_{i}}$

\subsubsection{Alternative waypoints}

The positioning of alternative waypoints is important to the design of RATCs. However, this problem is intractable, i.e., it cannot be solved in terms of a closed-form expression and thus does not have an analytic solution. Alternative waypoints must be artificially

20 extended beyond areas of heavy seas caused by the TC. If, as a result, the distance between adjacent alternative waypoints decreases considerably, it leads to a dramatic increase in calculation time. The number of possible waypoints cannot be very small, since that would adversely affect the economic benefit of adopting the route in question. Thus, alternative waypoints are determined by practical need, which is the second 25 boundary condition in our proposed model for minimizing the economic cost of RATCs. Alternative waypoints are shown in Fig. 2. 
In practice, it is much safer to bypass a TC from the left (right) side of the cyclone motion in the northern (southern) hemisphere, since cyclones rotate anticlockwise (clockwise). Therefore, only waypoints in the left (right) semicircle of the cyclone are considered in our proposed RATC algorithm.

\subsection{Algorithm design}

The algorithm to generate the most economical RATC is as follows (Fig. 3):

1. Assume that a ship at position $x_{0}$ begins to change course at time $t_{0}$ to avoid a TC, and that the next waypoint of the ship's original route is $x_{\text {end }}$. Divide the segment $x_{0} x_{\text {end }}$ of the route into $n$ parts of equal length $x_{i}(i=1,2, \ldots \ldots, n)$, and draw lines perpendicular to the segment $x_{0} x_{\text {end }}$ through each $x_{i}(i=1,2, \ldots \ldots, n)$. According to the range of the heavy weather area of the TC, $m$ points are chosen on the left semi-circular side of the TC for $x_{i}(i=1,2, \ldots \ldots, n)$. These points $x_{\mathrm{i}, \mathrm{j}},(i=1,2, \ldots, n ; j=1,2, \ldots, m)$ are the alternative waypoints for a ship's RATC (as shown in Fig. 2).

2. Beginning from point $x_{i-1, j}$ (when $i=1, x_{i-1, j}=x_{0}$ ), calculate separately the time and the cost to sail from $x_{i-1, j}$ to $x_{\mathrm{i}, \mathrm{k}},(k=1,2, \ldots, m)$. The time $t_{i, j, k}$ and cost $C_{i, j, k}$ of sailing from $x_{i-1, j}$ to alternative waypoints can be calculated using the following formulas:

$$
\begin{aligned}
& t_{i, j, k}=\int_{x_{i-1, j}}^{x_{i, k}} \frac{1}{v_{\text {ship }}(t, x)} \mathrm{d} x \quad(i=1,2, \ldots, n ; j, k=1,2, \ldots, m) ; \\
& C_{i, j, k}=\int_{t_{i-1, j}}^{t_{i, k}}\left\{C_{\text {oil }}\left(\Delta, V, Q_{\mathrm{a}}\right)+C_{\mathrm{t}}\right\} .
\end{aligned}
$$

Take account of the decrease in the ship's speed over time $v_{\text {ship }}(t, x)$ due to turbulent waves, the external environment and the ship's course. Real-time data for the velocity of the wind, the waves, and the current can be obtained from the forecasting results of numerical model.

3. Ascertain if there is an un-navigable area in a segment of the route $x_{i-1, j} x_{i, k}$. According to the environmental conditions of the ship's current position, the capsizing probability can be calculated in relation to the acceptable capsizing probability level. If the capsizing probability is acceptable, go to (4). If it is unacceptable, then $C_{i, j, k}=+\infty$.

4. Calculate the minimum cost $\mathrm{CC}_{i, k}=\min _{j}\left(C_{i, j, k}\right)$ and time $\mathrm{tt}_{i, k}$ to reach the point $x_{i, k}$. If $\mathrm{CC}_{i, k}=+\infty, x_{i, k}$ is an un-navigable point that cannot be reached from any of the segments, it will not be used to select the next segment.

5. Set $i=i+1$ and repeat steps 2 to 5 until $i=n$. The minimum cost segments that connect to $x_{\text {end }}$ (which is $x_{n 1}$ ) when taken together form the shortest route $X_{0} X_{1} X_{2} \ldots \ldots X_{\text {end }}$ to the destination that avoids the TC. The time taken by the ship to arrive at each waypoint is $T_{0}, T_{1}, T_{2}, \ldots \ldots, T_{n}$ respectively.

In practice, the fewer the waypoints, the better is the route. Fewer waypoints imply fewer changes in direction and smaller loss of speed, resulting in a more efficient route. Thus, the RATC is optimized to reduce waypoints at no additional cost.

The optimization algorithm is illustrated as follows (Fig. 4):

1. The positions of the waypoints, which are the result of the shortest-time RATC as discussed in the last section, are $\mathrm{xx}_{i},(i=0,1, \ldots, n)$. The time a ship takes to reach waypoint $\mathrm{xx}_{i}$ is $\mathrm{tt}_{i}$ and the cost to arrive at this point is $\mathrm{CC}_{i}$. Set $i=0$, and continue to the next step.

25 2. Starting from $\mathrm{xx}_{i}$, calculate the cost $\mathrm{cc}_{j}$ of the ship's motion along the segment $\mathrm{xx}_{i} \mathrm{xx}_{j}$ from $\mathrm{xx}_{i}$ to $\mathrm{xx}_{j}(j=i+1, i+2, \ldots)$. Check for un-navigable areas in segment 
$\mathrm{xx}_{i} \mathrm{Xx}_{j}$ in relation to changing wind and wave conditions. Let $z=j-1$ if there is an un-navigable area.

3. Let $\mathrm{dc}=\mathrm{Cc}_{z}-\mathrm{cc}_{i}$ and $\mathrm{DC}=\mathrm{CC}_{z}-\mathrm{CC}_{i}$. If $\mathrm{dc} \leq \mathrm{DC}$, then $i=z$. Assign the values of $\mathrm{xx}_{i}$ and $\mathrm{CC}_{i}$ to $x_{-}$ok and $c_{-}$ok, respectively. If $\mathrm{dc} \geq \mathrm{DC}$, set $z=z-1$ and repeat step 3. Otherwise, proceed to the next step.

4. Let $i=z$. Repeat steps 2 to 4 until $z=n$. Here, $x_{-}$ok represents the waypoints and $c \_$ok is the cost of the ship's optimized RATC.

\section{Case study and results}

The TC Nock-ten was used to test the model. Noc-kten's track every six hours is shown

10 in Fig. 5. Nock-ten made landfall at Wenchang in the Hainan province of China in 2011. Winds around the center of the storm were as strong as $25 \mathrm{~m} \mathrm{~s}^{-1}$ at landing time. The direct economic loss from Nock-ten was estimated at $\$ 600$ million, and two people were killed. Nock-ten also seriously affected shipping service in the region.

Let us assume that a ship was at $19^{\circ} \mathrm{N}, 111.5^{\circ} \mathrm{E}$ at 00:00 Coordinated Universal 15 Time (UTC) on 28 July 2011, and that the crew took action to avoid the TC as soon as the warning was received. Let us also assume that the next waypoint of the ship's original route was $20.5^{\circ} \mathrm{N}, 120^{\circ} \mathrm{E}$. The parameters of the ship are shown in Table 2. The ship is valued as 23.8 million $\$$ and its cargo at 34.9 million $\$$. The price of oil at the time was $871 \$ \mathrm{t}^{-1}$. The benefit that the ship creates was $11100 \$$ day $^{-1}$, whereas 20 the fuel consumption was $24 \mathrm{tday}^{-1}$ at a speed of $10 \mathrm{kn}$. We ignore the change in the ship's displacement and assume the ship's speed keeps constant.

\subsection{Numerical simulation of TC}

The WRF model is used to simulate the TC. In the model, the $1^{\circ} \times 1^{\circ}$ National Center for Environmental Prediction (NCEP) data for 10:00 UTC on 28 July 2011, is used as initial

$$
4923
$$

data. NCEP data at six-hour intervals is used as the boundary data. The domain of the simulation is $99-130^{\circ} \mathrm{E}$ and $0-30^{\circ} \mathrm{N}$. The resolution is $0.1^{\circ} \times 0.1^{\circ}$ and the time step is $300 \mathrm{~s}$. The wind field forecasted by the WRF is used to drive the WaveWatchlll. The resolution of the wave model is $0.1^{\circ} \times 0.1^{\circ}$ and the time step is $900 \mathrm{~s}$. The resolution of 5 the wave direction is $15^{\circ}$. The results of the two models are shown in Fig. 6.

\subsection{The ship's capsizing probability}

To calculate the probability of the ship capsizing, the range of integration time is set to $0-300 \mathrm{~s}$, the time step to $0.0125 \mathrm{~s}$, the upper limit of the wave-power spectrum to $4.5 \mathrm{rad} \mathrm{s}^{-1}$, the frequency interval $\varpi$ to $0.025 \mathrm{rad} \mathrm{s}^{-1}$, and effective wave slope $\alpha_{0}$ is 10 set to 0.729 . The variation in the probability of the ship capsizing in relation with its course and the wave direction are shown in Fig. 7a. For a wave of the same height, the probability of capsizing is maximized if the wave is perpendicular. The probability of the ship capsizing increases with increasing wave height (Fig. 7b). The variation in the probability of capsizing with varying wave height and angle between the ship's heading 15 and the wave direction is show in Fig. 7c.

The probability of the ship capsizing under waves of different heights for different headings of the ship at 10:00 UTC on 28 July 2011, is shown in Fig. 8. The probability of the ship capsizing is found to be sensitive to the angle between the ship's heading and the direction of the wave. Thus, the RATC must take these into consideration. The 20 probability of the ship capsizing is relatively small with stern waves or when the vessel is sailing head to sea.

\subsection{Economy and safety route design}

The probability of the ship capsizing when heading in different directions and at different times is calculated based on forecast results from the numerical models. The 25 alternative waypoints are shown in Fig. 2, where the interval perpendicular to the original route is $0.35^{\circ}$. The ship's speed is taken to be constant. The acceptable probability 
of capsizing for different routes is listed in Table 3. To compare the model's performance against competing methods, the sector diagram typhoon avoidance method was used. In Fig. 9, points $A, B$, and $C$ represent, respectively, the location of the center of the tropical cyclone at 00:00, 06:00 and 12:00 UTC on 28 July 2011. $H_{1}, H_{2}$ and $H_{3}$, re-

5 spectively, represent the ship's location at each of these times. The result of the sector diagram typhoon avoidance method is marked as "Exp6" The ship's experimental RATCs are shown in Fig. 10a.

Exp1-Exp3 (the ship has the same acceptable probability of capsizing but at different speeds) are taken as a group to test the influence of the ship's speed on the probability

10 of capsizing. Although the speed in Exp3 is higher (1 kn) than in Exp2, the shipping time is only $0.1 \mathrm{~h}$ less than Exp2. This means that the environment is different in these two cases. The route has to be chosen in consideration of the changing environment. For Exp3 (Fig. 10a), the ship has to travel a longer distance to avoid the high-risk area. This shows that higher speed does not necessarily imply smaller sailing time, as might

15 be expected. Given the same acceptable probability of capsizing, the safety probability of the RATC also varies with ship speed. The median $(16 \mathrm{kn})$ speed among the three speeds in Table 3 has the smallest cost-benefit ratio. This group experiment shows that the ship's speed is not the only factor influencing the cost-benefit ratio of the RATC.

Exp3-Exp5 are taken as a group to test the effect of acceptable capsizing probabil-

20 ity on the cost-benefit ratio of the RATC. In this group, a high risk (high probability of capsizing) can reduce shipping time but it does not mean it can reduce the cost-benefit ratio. Although Exp5 has the lowest acceptable capsizing probability, its cost-benefit ratio is not the smallest in the group. Compared to the sector diagram typhoon avoidance method (Exp6), the RATC from our proposed model can reduce the ship's risk.

25 At constant speed, the cost-benefit ratio of the RATC is smaller than that of the sector diagram typhoon avoidance method (see Exp3-Exp6).

In Fig. 10b, the ship's speed is $17 \mathrm{kn}$ and the acceptable probability of capsizing is $7 \times 10^{-4}$. The blue line represents the RATC before optimization whereas the red line shows the route after optimization. Figure $10 \mathrm{~b}$ shows that the optimal route can

4925

reduce the number of waypoints. Figure 11 indicates the ship's position at different times. The color spectrum at the bottom of the figure represents the probability of the ship capsizing when travelling in varying directions at different times.

Experimental results show that a higher speed does not necessarily imply a lower 5 cost in terms of time, as might be expected. Similarly, a lower cost in terms of time does not imply a smaller cost-benefit ratio for the route in question. Our case study shows that the cost of a ship's RATC is related not only to its speed, but also to the acceptable risk level. Under the same environmental conditions, the capsizing risk is related to factors affecting the ship's journey - for instance, the ship's sea-keeping ability. When

10 the risk (acceptable probability of capsizing) is chosen, a suitable speed for it can be calculated according to the cost-benefit ratio of the RATC. Compared to the sector diagram typhoon avoidance method, the routes provided by our model are safer and more economical.

\section{Conclusions and discussion}

15 In this paper, we designed and presented a method to calculate a safe and economical RATC based on dynamic forecasting environments. The cost-benefit ratio (Ra) index of RATC is proposed to compare the bad or good of different RATC. Case study shows that compared with the Sector diagram typhoon avoidance method, the model proposed in this paper is much more conforming to the actual needs of navigation 20 practice.

The traditional methods which are used in navigation practice depend on crew experience to assess the ship risk in TCs to a very great degree. The wave resistances of different ships are very different, it is unreasonable to only use a certain wind speed (such as 34KT rule, Holweg, 2000, the Diagram of the 1-2-3 rule, Wisniewski et al.,

25 2009) as a restriction condition to design the RATC. Trying to avoid or reduce the uncertainty of human experience when assessing the ship risk, in our model, we used the ship capsizing probability to quantify the ship risk in TC conditions. The method 
proposed by Gu (2006b) was used to solve the FPK equation. Case study also shows that the ship capsizing probability is very sensitive to the ship heading when the wave field are certain. In other words, if we can choose the right heading when avoiding TCs, the ship risk can be lower much (see Fig. 8), even in the same wave conditions.

5 Although the accuracy of environmental forecast data is ever improving, forecast errors still occur and need to be corrected. In most study of weathering routing, the environment forecast errors are neglected. Our model took into account error distribution to reduce the influence of the errors on the capsizing probability. In this way, the proposed model can reduce the probability that the ship sail into the high risk area because of

10 the forecast errors. The ship speed loss has been researched more than thirty years, but it is still a hard issue to be solved. In our model, we used the newly results of $\mathrm{He}$ and Dong (2009) to calculate the ship positions in a TC. To reduce the computation time of the model, in the algorithm of the model, the alternative waypoints should be artificially extended beyond areas of heavy seas caused by the TC.

The case study shows that the cost-benefit ratio of RATC is related not only ship speed but also the acceptable level of risk. Not a single factor of them can decide the cost-benefit ratio of RATC. A good combination of ship speed and acceptable level of risk is the determinant of a low cost-benefit ratio of a RATC. An acceptable level of risk should be set in light of the particular features of the vessel at hand as well as the risk

20 tolerance of the company in question. Based on acceptable risk levels and the costbenefit ratio under different speeds, the optimal speed to avoid TCs can be figured out. By comparing it with the traditional method (sector diagram typhoon avoidance method), we showed that our proposed model not only ensures ship safety but also reduces shipping cost.

25 We have considered the following directions for future research in this field:

1. The joint effect of the wind and the waves will be included when calculating the probability of capsizing. In this paper, we only considered the effect of waves. Considering the joint effect of the wind and the waves will improve the accuracy of our method in calculating the probability of capsizing.

$$
4927
$$

2. We intend to address the rapid increase in computation time for higher spatial resolution of alternative waypoints. When alternative waypoints are numerous, computation cost increases dramatically. We will need to design an intelligence algorithm to solve this problem.

3. We will also take into account the comfort level of crew on board the ship.

Acknowledgements. This work is supported by the National Science Foundation of China (NSFC) through Grants D0512/40805063, State Key Laboratory of Tropical Oceanography (South China Sea Institute of Oceanology, Chinese Academy of Science).

\section{References}

10 Andrejev, O., Soomere, T., Sokolov, A., and Myrberg, K.: The role of the spatial resolution of a three-dimensional hydrodynamic model for marine transport risk assessment, Oceanologia, 53, 309-334, 2011.

Azaron, A. and Kianfar, F.: Dynamic shortest path in stochastic dynamic networks: ship routing problem, Eur. J. Oper. Res., 144, 138-156, 2003.

15 Aertssen, G.: Service Performance and Trials at Sea, Performance Committee of 12th ITTC, 233-265, Rome, CEBERENA, 1969.

Bedard, R.: Feasibility of Using Wavewatch III for Days-Ahead Output Forecasting for Grid Connected Wave Energy Projectsin Washington and Oregon. Electric Power Research Institute, 78 pp., available at: http://oceanenergy.epri.com/attachments/wave/reports/Wave Forecasting_Final_Report.pdf (last access: 1 August 2014), 2008.

Bikdashi, M. Balachandran, B., and Nayfeh, A.: Melnikov analysis for a ship with a general roll-damping model, Nonlinear Dynam., 6, 101-124, 1994.

Chen, H.: A Minimum Cost Dynamic Program for Ship Routing under Uncertainty, Ph.D. thesis, Department of Ocean Engineering, MIT, Cambridge MA, America, 163 pp., 1978.

25 Chen, J. H. and Zhang, J. P.: Navigation Meteorology and Oceanography, Dalian Maritime University Press, Dalian, China, 303 pp., 2004 (in Chinese).

Christiansen, M., Fagerholt, K., and Ronen, D.: Ship routing and scheduling: status and perspectives, Transport. Sci., 38, 1-18, 2004. 
Chu, P. C., Qi, Y. Q., Chen, Y. C., Shi, P., and Mao, Q. W.: South China Sea wind-wave characteristics, Part I: Validation of Wavewatch-III using TOPEX/Poseidon data, J. Atmos. Ocean. Tech., 21, 1718-1733, 2004.

Delitala, A. M. S., Gallino, S., Villa, L., Lagouvardos, K., and Drago, A.: Weather routing in long-distance Mediterranean routes, Theor. Appl. Climatol., 102, 125-137, 2010.

Falzarano, M., Shaw, S. W., and Troesh, A. W.: Application of global methods for analyzing dynamic systems to ship rolling motion and capsizing, Int. J. Bifurcat. Chaos, 2, 101-115, 1992.

Gu, J, Y.: Nonlinear rolling motion of ship in random beam seas, J. Mar. Sci. Technol., 12, 273-279, 2004.

Gu, J. Y.: Calculation of ship rolling probability using a new path integration method, Journal of Ship Mechanics, 10, 43-52, 2006a.

Gu, J. Y.: Probability analysis of ship nonlinear roll-motion excited by white noise, Journal of Ship Mechanics, 10, 18-25, 2006b.

$15 \mathrm{Gu}$, J. Y. and Miao, Z. H.: Numerical simulation of ship's safe probability in stochastic waves, Journal of Jiangsu University of Science and Technology (Natural Science Edition), 19, 6-11, 2005 (in Chinese).

Guo, Y. Y. and Hou, Y. J.: Statistical analysis of ocean wave numerical forecast error, Marine Science, 34, 65-68, 2010 (in Chinese).

20 Hagiwara, H.: Weather routing of (sail-assisted) motor vessels, Ph.D. thesis, Technical University of Delft, Delft, Netherlands, 340 pp., 1989.

He, H. M., Dong, G. X., and Jiang Y. X.: Approximate estimation for ship speed loss in wave, Journal of SSSRI, 32, 6-9, 2009.

Holweg, E. J.: Mariner's guide for hurricane awareness in the North Atlantic Basin. United States: National Weather Service, available at: http://www.nhc.noaa.gov/marinersguide.pdf, (last access: 18 May 2012)., 2000.

Hopkins, J. S.: The Accuracy of Wind and Wave Forecasts, Health and Safety Executive,Offshore Techology Report, London, 1997.

Huang, Y. S., Wang, Z., and Li, H. T.: Caclulation of the capsizing probability of ship at beam wind and sea, Journal of Tianjin University, 34, 651-654, 2001 (in Chinese).

James, R. W.: Application of Wave Forecast to Marime Naviagation, US Navy Hydrographic Office, Washington., 1957.

4929

Kaplan, R.: Lecture notes on nonlinear theory of ship roll motion in a random seaway, 11 th ITTC, Tokyo, 393, 11-20 October, 1966.

$\mathrm{Li}, \mathrm{C}$. , Yang, B., and Zhang, Y. S.: Estimation methods of the ship's speed-loss in wind and waves, Ship Science and Technology, 33, 27-30, 2011 (in Chinese).

5 Liu, D. G., Wang, D. Q., and Wu, Z. L.: Safe-economic decision making model of ship's avoidance routing to tropical cyclone, Journal of Traffic and Transportation Engineering, 5, 94-98, 2006 (in Chinese).

Magirou, E. F. and Psaraftis, H. N.: Quantitative Methods in Shipping: a Survey of Current Use and Future Trends, Athens University of Economics and Business, Report No. E115, Athens,

10 Greece, 1992.

Maki, A., Akimoto, Y., Nagata, Y., Kobayashi, S., Kobayashi, E., Shiotani, S., Ohsawa, T., and Umeda, N.: A new weather-routing system that accounts for ship stability based on a realcoded genetic algorithm, J. Mar. Sci. Technol., 16, 311-322, doi:10.1007/s00773-011-0128z, 2011.

15 McCord, M. R., Young-Kyun, Lee, and Hong Kam Lo.: Ship routing through altimetry-derived ocean currents, Transport. Sci., 33,49-67, 1999.

Padhy, C., Sen, D., and Bhaskaran, P.: Application of wave model for weather routing of ships in the North Indian Ocean, Nat. Hazards, 44, 373-385, 2008.

Panigrahi, J., Tripathy, J., and Umesh, P.: Optimum tracking of ship routes in $3 g$-WAM simulated rough weather using IRS-P4 (MSMR) analysed wind fields, J. Indian Soc. Remote Sens., 36, 141-158, 2008.

Shen, D. and Huang, X. L.: Lasting time before capsize of ship in random beam waves, Shipbuilding of China, 41, 14-21, 2000 (in Chinese).

Shi, X. H., Zhang, J., and Wang, S.: Analysis of rolling capsizing probability of warship under random wind and beam seas, Journal of Ship Mechanics, 15, 473-479, 2011 (in Chinese).

Soda, T., Shiotani, S., Makino, H., and Shimada, Y.: Simulation of weather and ocean for numerical ship navigation, in: Proceedings of the ASME 2011 30th International Conference on Ocean, Offshore and Arctic Engineering, Rotterdam, Netherlands, 19-24 June 2011, 1-8, 2011.

30 Tang, Y. G., Gu, J. Y., Zheng, H. Y., and Li, H. X.: Study on the ship capsize in random beam seas using Melnikov method, Journal of Ship Mechanics, 8, 27-34, 2004 (in Chinese). 
Tang, Y. G., Liu, L. Q., and Zheng, H. Y.: Safe basin method of predicting survival probability of ships in bow Seas and quartering seas, Journal of Tianjin University, 39, 1021-1025, 2006 (in Chinese).

Thompson, J. M. T.: Transient basins: a new tool for desighing ships against capsize, in: Pro-

5 ceedings IUTAM Symposium on the Dynamics of Marine Vehicles and Structures in Waves, 24-27 June, London, 325-331, 1990.

Thompson, J. M. T., Rainey, R. C. T., and Soliman, M. S.: Mechanics of ship capsize under direct and parametric wave excitation, Philos. T. R. Soc. Lond., 338, 1-13, 1992.

Tolman, H. L.: Validation of WAVEWATCH III version 1.15 for a global domain, NOAA/NWS/NCEP/OMB Technical Note Nr. 213, 33 pp., available at: http://polar.ncep.noaa. gov/mmab/papers/tn213/OMB_213.pdf, 2002.

Wisniewski, B., Medyna, P., and Chomski, J.: Application of the 1-2-3 rule for calculations of a Vessel's Route using evolutionary algorithms, TransNav - International Journal on Marine Navigation and Safety of Sea Transportation, 3, 143-146, 2009.

15 Wisniewski, B., and Kaczmarek, P.: Elements of tropical cyclones avoidance procedure, TransNav - International Journal on Marine Navigation and Safety of Sea Transportation, 6, 119-122, 2012.

Wu, J. L., Ma, X. X., Fan, Z. Z., Liu, D. G., and Liu, Z. J.: Benefit evaluation for ship's avoidance routing of tropical cyclone, Journal of Dalian Maritime University, 36, 31-34, 2010 (in Chinese).

Wu, L. C., Wen, Y. Q., Peng, S. Q., Zhang, J. F., and Xiao, C. S.: Optimizing the routing of ship's tropical cyclone avoidance based on the numerical forecasts, Nat. Hazards, 69, 781-792, 2013.

Zhang, W. J., Wei, S. Y., Li, Q., Liu, D. G., and Liu, Z. J.: Multilevel decision method of ship's tropical cyclone avoidance route using multisource track forecast, Journal of Traffic and Transportation Engineering, 10, 122-126, 2010 (in Chinese).

Table 1. The forecast error range division.

\begin{tabular}{lllllllll}
\hline forecast error subdivision (in $\mathrm{m})$ & {$[-2,-1.5]$} & {$[-1.5,-1]$} & {$[-1,-0.5]$} & {$[-0.5,0]$} & {$[0,0.5]$} & {$[0.5,1]$} & {$[1,1.5]$} & {$[1.5,2]$} \\
Probability in this error range & $7.59 \times 10^{-4}$ & $1.6 \times 10^{-2}$ & 0.12 & 0.34 & 0.36 & 0.14 & 0.02 & 0.001 \\
\hline
\end{tabular}


Table 2. Parameter values of the ship.

\begin{tabular}{llll}
\hline $\mathrm{L}$ & $171.7 \mathrm{~m}$ & $I_{0}$ & $1.070 \times 10^{7} \mathrm{~kg} \mathrm{~m}^{2}$ \\
$\mathrm{~B}$ & $16.8 \mathrm{~m}$ & $C_{1}$ & $0.871 \mathrm{~m}$ \\
$\Delta$ & $8000 \mathrm{t}$ & $C_{3}$ & $0.013 \mathrm{~m}$ \\
$B_{1}$ & $1.070 \times 10^{7} \mathrm{~kg} \mathrm{~m}^{2} \mathrm{~s}^{-1}$ & $\phi_{v 1}$ & $-1.39 \mathrm{rad}$ \\
$B_{2}$ & $1.070 \times 10^{7} \mathrm{~kg} \mathrm{~m}^{2}$ & $\phi_{v 2}$ & $1.39 \mathrm{rad}$ \\
$\omega_{0}$ & $0.807 \mathrm{rad} \mathrm{s}^{-1}$ & $T$ & $8 \mathrm{~m}$ \\
\hline
\end{tabular}

4933

Table 3. Experimental results.

\begin{tabular}{lllllllll}
\hline No. & $\begin{array}{l}\text { Ship } \\
\text { speed }(\mathrm{kn})\end{array}$ & $\begin{array}{l}\text { Acceptable capsizing } \\
\text { probability Pa }\end{array}$ & $\begin{array}{l}\text { Maximum wind in } \\
\text { the sailing }\left(\mathrm{m} \mathrm{s}^{-1}\right)\end{array}$ & $\begin{array}{l}\text { Maximum wave in } \\
\text { the sailing }(\mathrm{m})\end{array}$ & $\begin{array}{l}\text { Shipping } \\
\text { time }(\mathrm{h})\end{array}$ & $\begin{array}{l}\text { Safety } \\
\text { probability }\end{array}$ & $\begin{array}{l}\text { Cost (thousand } \\
\text { dollar) }\end{array}$ & $\begin{array}{l}\text { Logarithm of cost- } \\
\text { benefit ratio } \lg (\mathrm{Ra})\end{array}$ \\
\hline Exp1 & 15 & 0.001 & 18.1 & 5.2 & 46.6 & 0.9991 & 81.37 & -2.858 \\
Exp2 & 16 & 0.001 & 17.8 & 5.3 & 41.6 & 0.9992 & 76.60 & -2.884 \\
Exp & 17 & 0.001 & 20.1 & 4.4 & 41.5 & 0.9991 & 79.71 & -2.867 \\
Exp4 & 17 & 0.002 & 20.1 & 4.4 & 40.7 & 0.9980 & 78.17 & -2.875 \\
Exp5 & 17 & 0.0007 & 20.1 & 4.4 & 41.5 & 0.9993 & 79.71 & -2.867 \\
Exp6 & 17 & 1 & 20.7 & 4.2 & 40.9 & 0.9959 & 78.56 & -2.866 \\
\hline
\end{tabular}




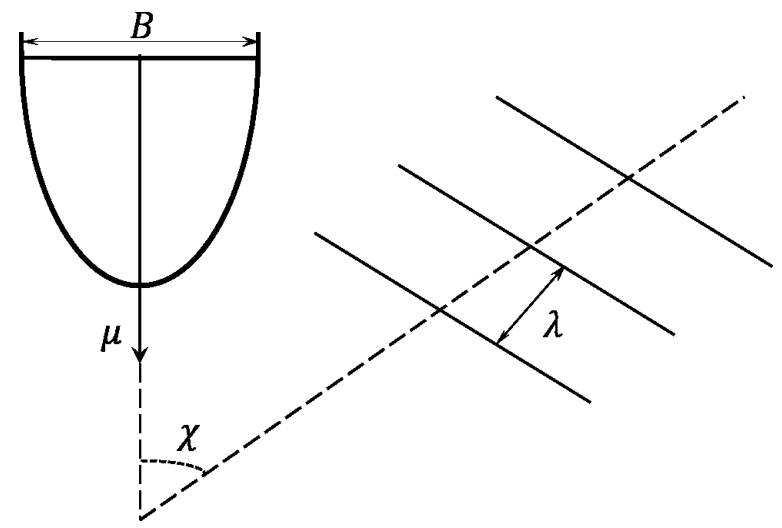

Figure 1. The wave encounter angle.

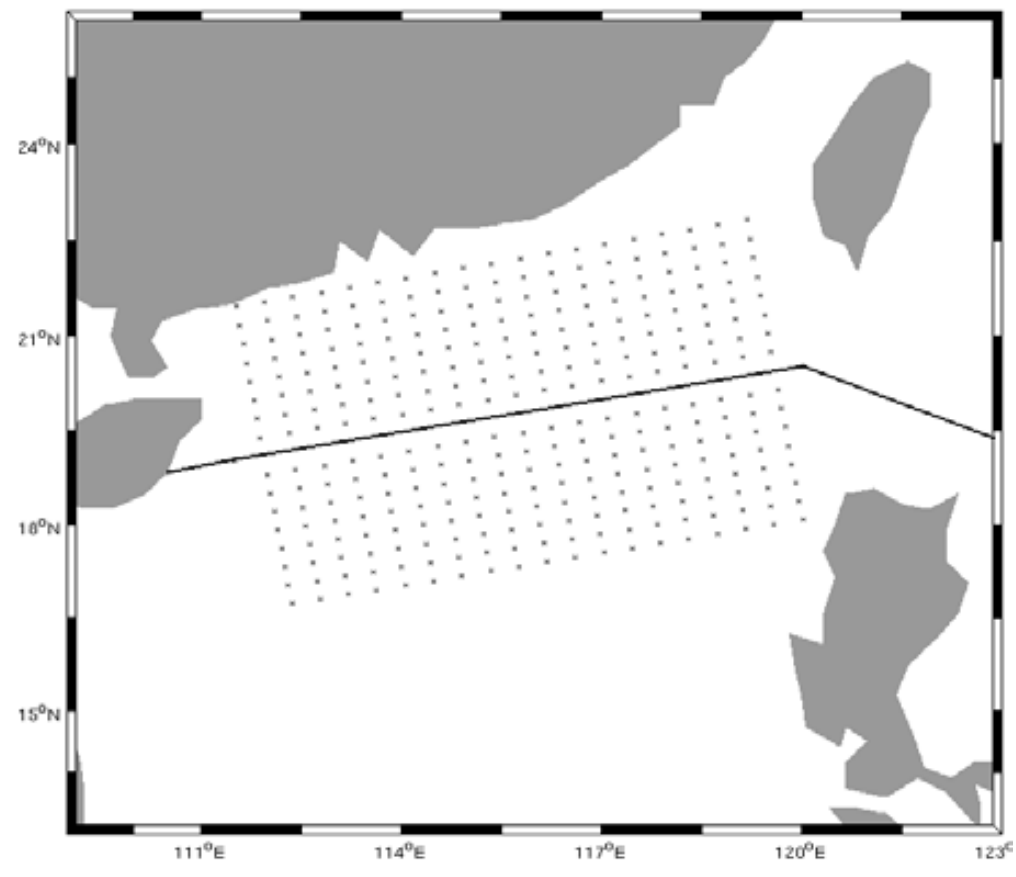

Figure 2. Sketch of alternative waypoints. 


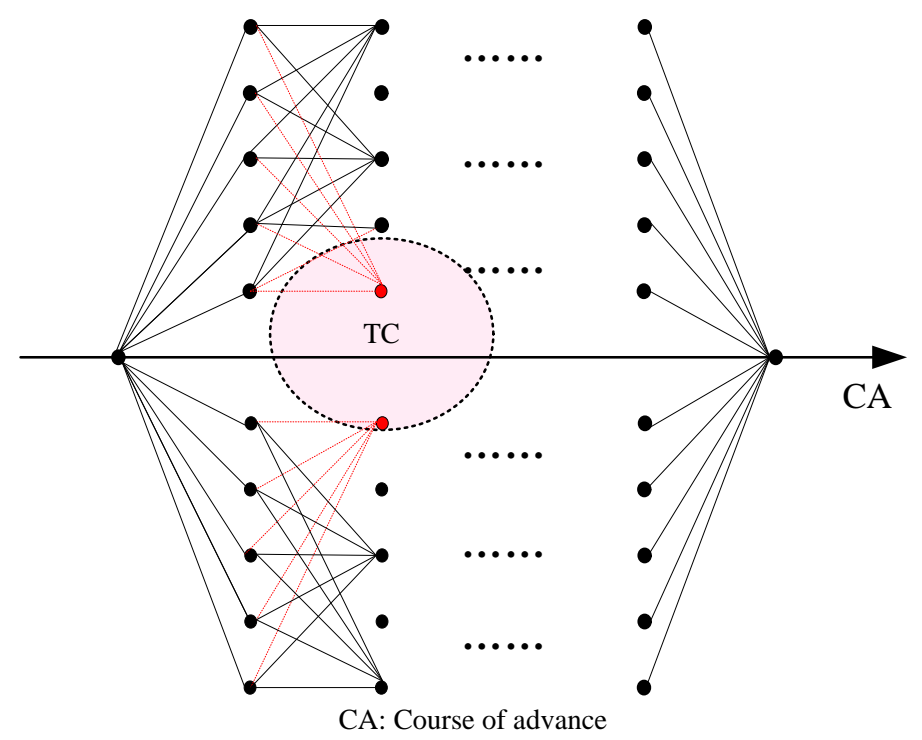

- unnavigable waypoints • alternative waypoints __ navigable segment un-navigable segment TC: un-navigable area of tropical cyclone

Figure 3. A route designed to avoid TC (the unnavigable waypoint is the point that all segments cannot reach).

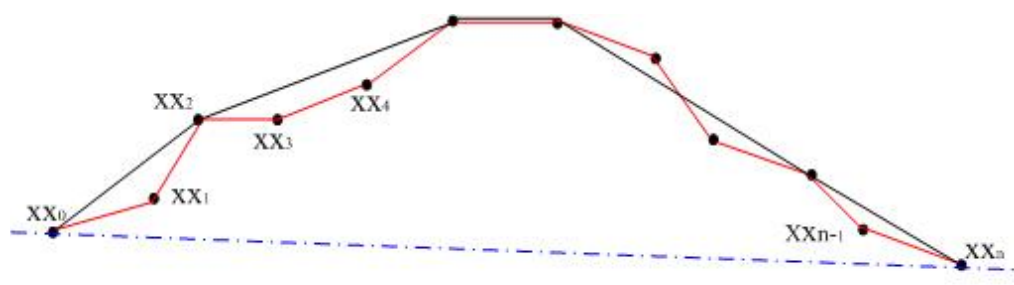

$-\cdot-$ Original route $\longrightarrow$ RATC Optimized RATC

Figure 4. Optimized RATC. 


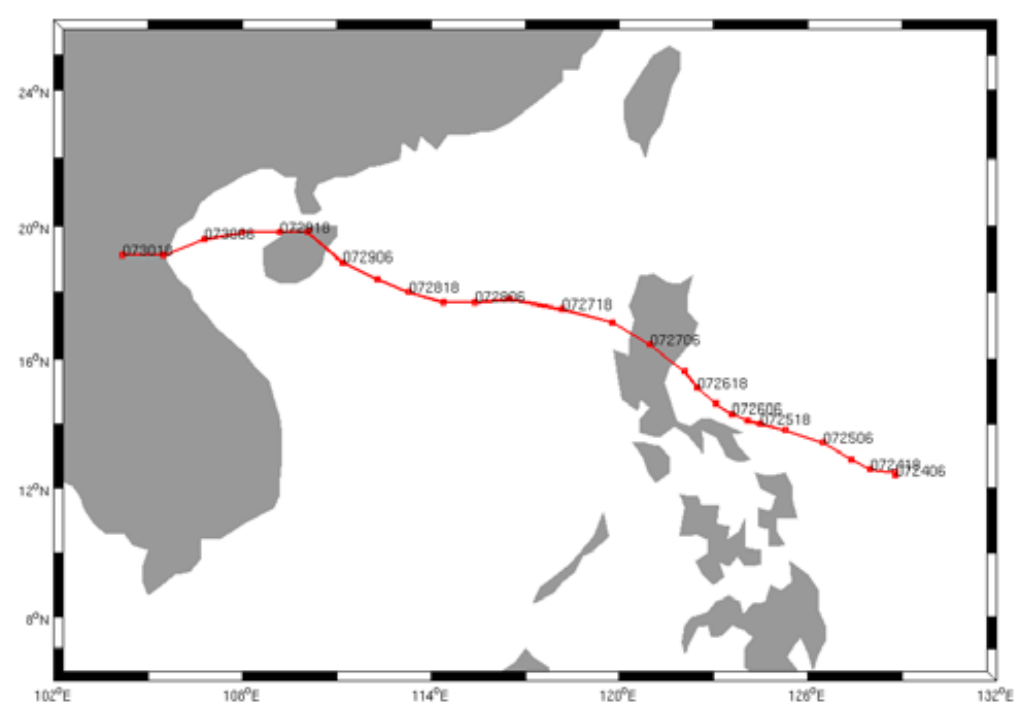

Figure 5. The track of TC Nockten every six hours.
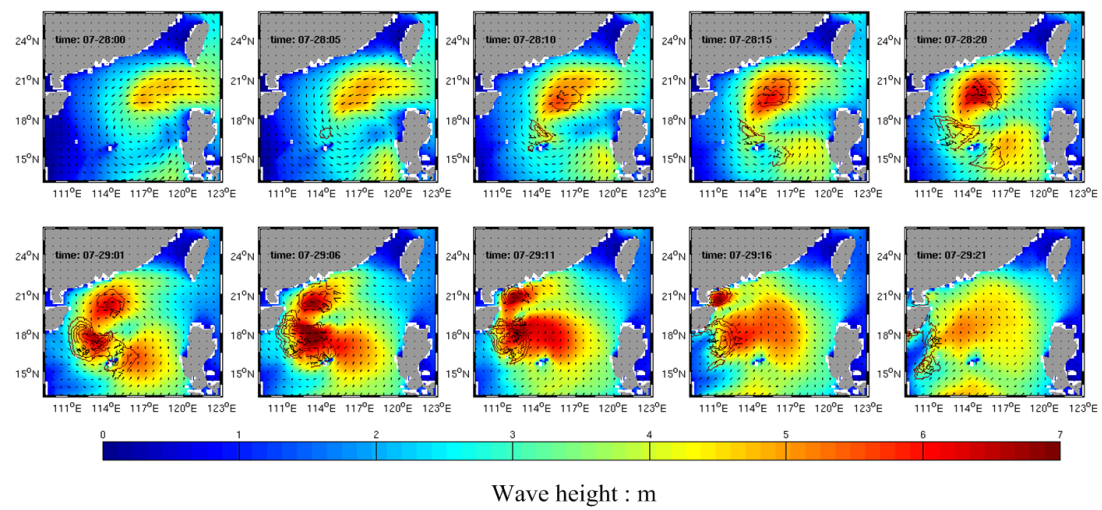

Figure 6. The forecast wind and wave conditions. 

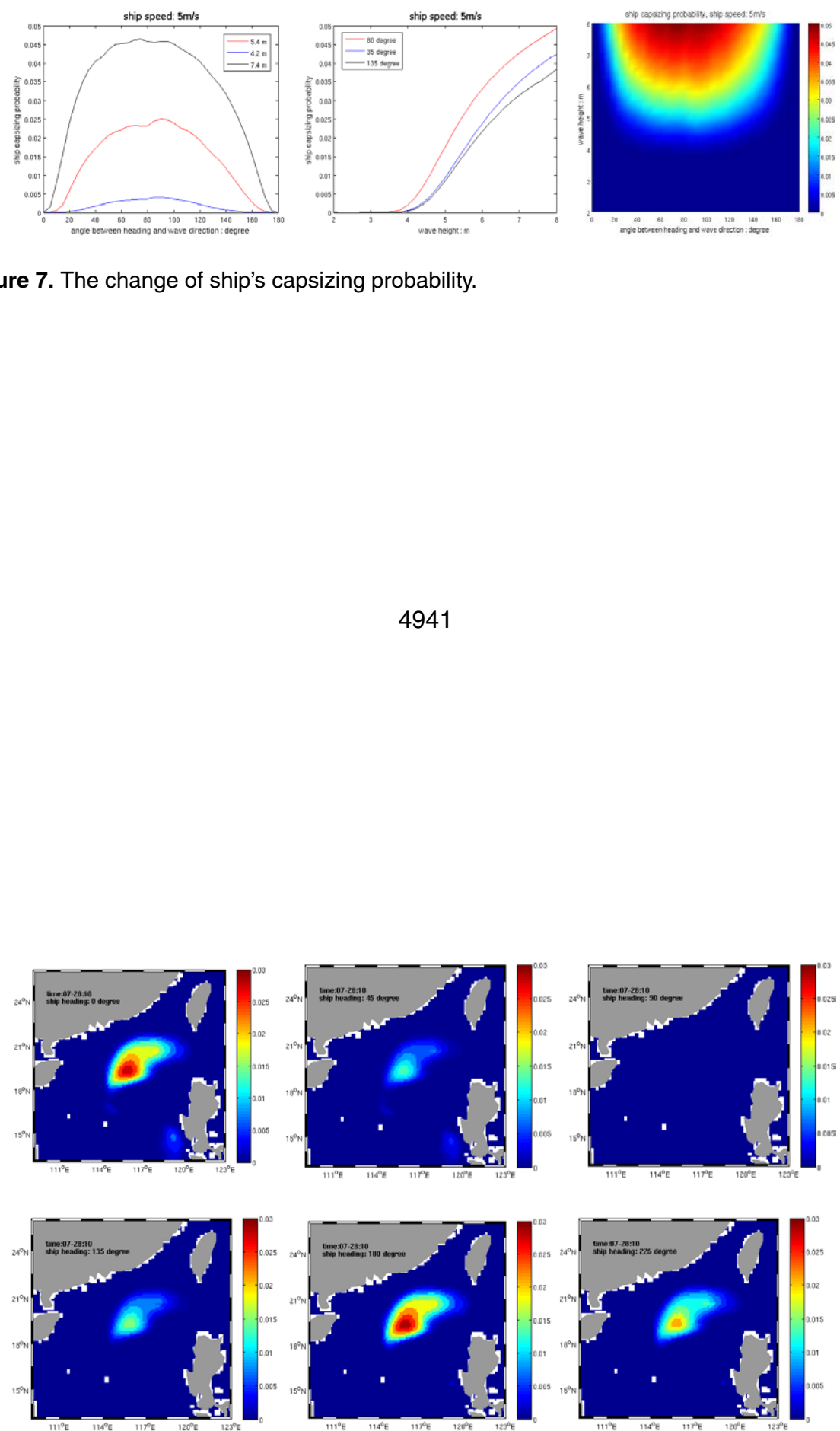

Figure 8. The ship's capsizing probability at different ship headings on 28 July $2011,10: 00$ (UTC). 


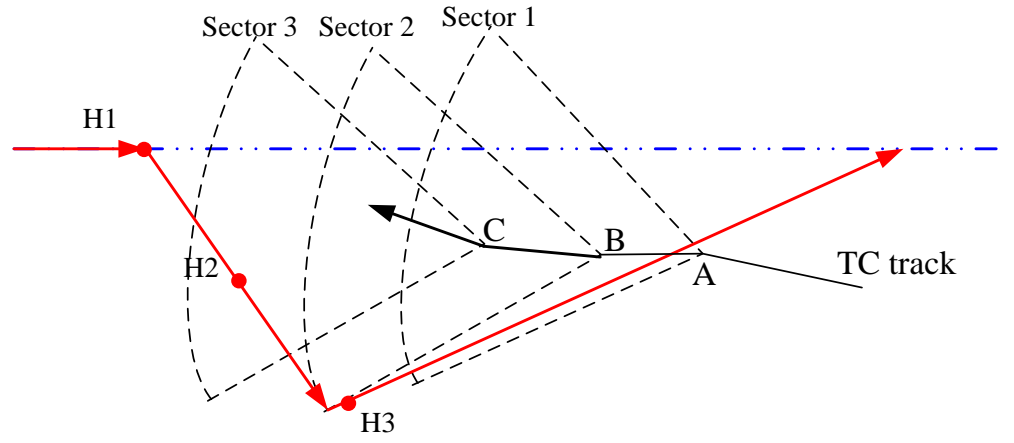

Figure 9. Sector diagram typhoon avoidance method.
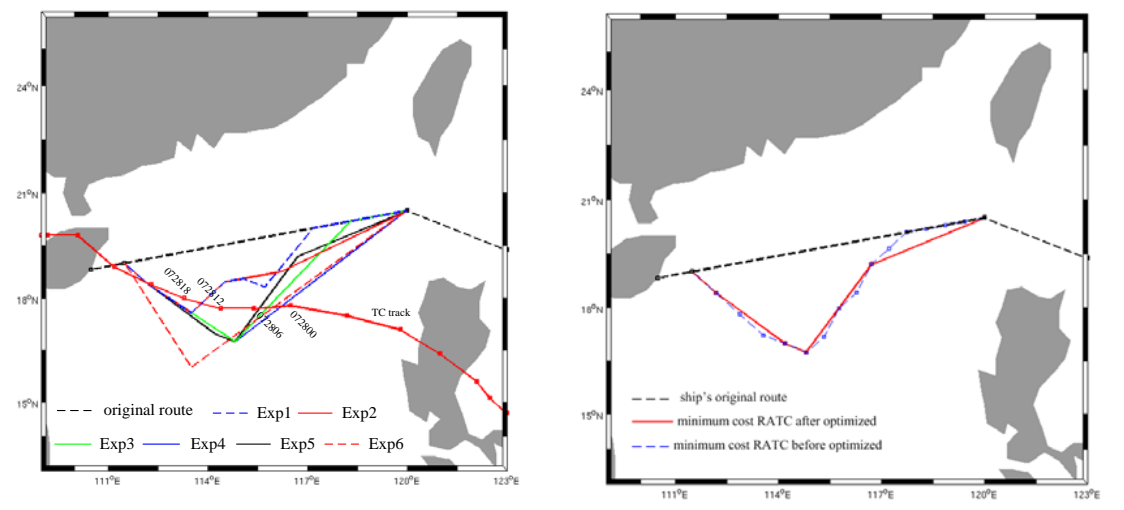

Figure 10. (a) Experimental routes (b) The route before and after the optimization experiment Exp5. 


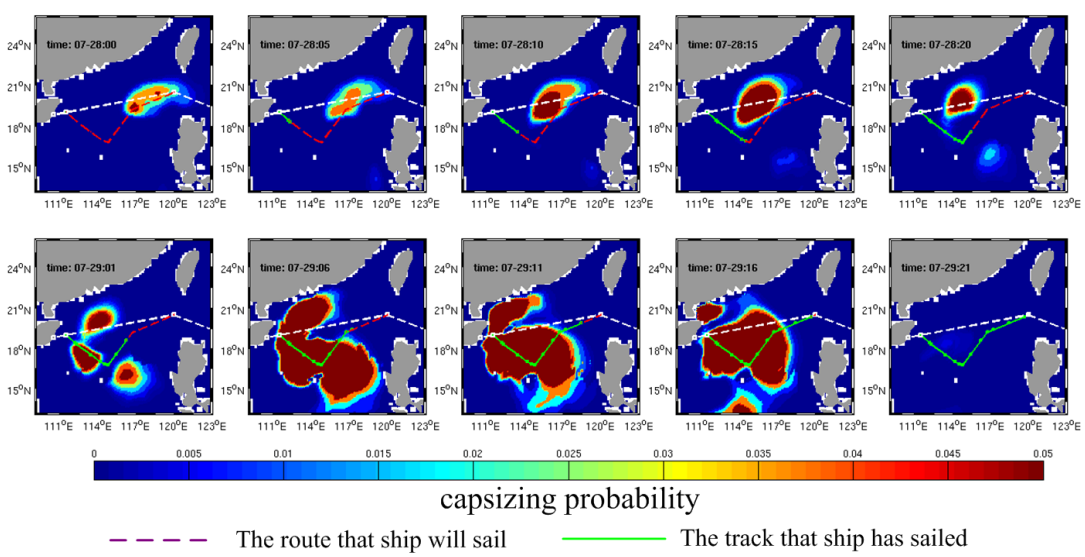

Figure 11. Ship position and the capsizing probability at different times. 